\title{
BMJ Open Randomised controlled trial to evaluate the influence of mHealth and eHealth skin cancer prevention education among young organ transplant recipients: the HIPPOlino intervention study
}

\author{
Silke Böttcher, ${ }^{1}$ Christoph Buck, ${ }^{1}$ Hajo Zeeb, ${ }^{1,2}$ Gudrun Laschewski, ${ }^{3}$ \\ Carolin Hauer, ${ }^{4}$ Gunnar Wagner, ${ }^{5}$ Michael Max Sachse ${ }^{5}$
}

To cite: Böttcher S, Buck C, Zeeb H, et al. Randomised controlled trial to evaluate the influence of mHealth and eHealth skin cancer prevention education among young organ transplant recipients: the HIPPOlino intervention study. BMJ Open 2019;9:e028842. doi:10.1136/ bmjopen-2018-028842

- Prepublication history for this paper is available online. To view these files, please visit the journal online (http://dx.doi. org/10.1136/bmjopen-2018028842).

Received 28 December 2018 Revised 19 August 2019 Accepted 16 October 2019

Check for updates

(c) Author(s) (or their employer(s)) 2019. Re-use permitted under CC BY-NC. No commercial re-use. See rights and permissions. Published by BMJ.

For numbered affiliations see end of article.

Correspondence to

Silke Böttcher;

boettcher@leibniz-bips.de

\section{ABSTRACT}

Objectives To determine whether a multicomponent sun protection intervention programme (mHealth) for young organ transplant recipients (OTR) leads to a higher increase of preventive knowledge and behavioural change than an e-learning education programme (eHealth).

Design Randomised controlled trial with one preintervention baseline survey and three follow-up surveys after 6 weeks, 6 and 12 months. Comparison of two different intervention schedules with a control group (CG).

Setting Multicomponent sun protection trainings in Germany, the Netherlands and Austria between June 2013 and September 2015.

Participants 137 0TRs (5-22 years of age, 61

females/76 males) participated in the study.

Interventions (A) Intervention group 1 (IG1):

personal training with subsequent forwarding of individual ultraviolet index-dependent sun protection recommendations via short message service (SMS); (B) intervention group 2 (IG2): e-learning training without SMS; (C) CG: regular information letters, online training after 1 year.

Outcome measures Key questions were used to form a knowledge and a behavioural score. Behavioural strategies and knowledge were quantified through self-administered questionnaires.

Results Analyses 6 weeks after the intervention showed a higher knowledge increase in both IG compared with the CG (IG1 to CG: OR $12.64,95 \%$ Cl 4.20 to 38.20 ; IG2 to CG: $\mathrm{OR} 2.59,95 \% \mathrm{Cl} 0.95$ to 7.04$)$. Sun protection behaviour improved slightly but not significantly in both IG (IG1 to CG: OR $2.56,95 \% \mathrm{Cl} 0.93$ to 7.00 ; IG2 to CG: OR 1.22 , $95 \% \mathrm{Cl} 0.45$ to 3.32). One year after the intervention, no behavioural changes were observed in either IG compared with the CG. IG1 but not IG2 still scored significantly higher in sun protection knowledge than the CG 1 year after intervention (IG1 to CG: OR 4.46, 95\% $\mathrm{Cl} 1.48$ to 13.43 ; IG2 to CG: OR $1.41,95 \% \mathrm{Cl} 0.51$ to 3.93 ).

Conclusions This multicomponent sun protection programme provides a promising strategy to increase sun protection knowledge and possibly also protective behaviour in young OTR.

Trial registration number DRKS00011393.

\section{Strengths and limitations of this study}

- This is the first German randomised controlled trial to evaluate a multicomponent sun protection programme in organ transplant recipient (OTR) using TmHealth and eHealth approaches for a follow-up period of 1 year.

- A scoring system was developed to quantify sun protection knowledge and behaviour before and after intervention.

- The generalisability of the findings may be limited due to the low sample size of 137 OTRs.

- Findings of this behavioural study may be influenced by factors such as self-report, social desirability and recall bias, as well as parental participation for children aged less than 12 years.

\section{INTRODUCTION}

The risk of skin cancer rises with increasing age and is associated with factors such as the cumulative and the intermittent ultraviolet (UV) light exposure or the individual skin type. ${ }^{1}$ Organ transplant recipients (OTR) also have an increased risk due to their lifelong need for immunosuppressive treatment. ${ }^{23}$ Children and adolescents who were transplanted in early childhood represent a high-risk group. Forty to fifty per cent of all incident tumour illnesses after transplantation are reported to be tumours of the skin. ${ }^{4}$ The risk of developing non-melanoma skin cancer is 65-250 times higher in OTRs compared with immunocompetent persons. ${ }^{5}$ Skin cancer prevention builds on a reduction of UV exposure. The increase of knowledge is one cornerstone to improve preventive behaviours including sun avoidance, covering the skin surface and use of sunscreen. ${ }^{6}$ Even though these strategies appear straightforward, previous studies showed that many 
OTRs are unaware of their increased skin cancer risk and do not protect themselves accordingly. ${ }^{6-10}$ Studies have shown that knowledge-regardless of the topic — can be increased through both face-to-face and online training. However, face-to-face training is rated much more positively than pure online learning. ${ }^{1-13}$ Mobile health (mHealth) is one promising approach in cancer prevention, with text message (short message service, SMS)based programmes being used worldwide. ${ }^{14}$

In paediatric and in adolescent transplant patients as well as in children suffering from inflammatory bowel disease, text messaging also improved medical adherence. ${ }^{15-17}$

Previous studies reported improvements of sun protection behaviour through SMS-based interventions in young populations. ${ }^{18-20}$ The HIPPOlino feasibility study (German mnemonic for skin cancer intervention and prevention programme for OTR) showed that individual sun protection recommendations (eg, adapted to the residential location) are technically feasible and well accepted among young OTRs. ${ }^{21}$ The HIPPOlino intervention study aimed to evaluate a standardised training programme for children and adolescents after organ transplantation. We examined whether an SMS-supported personal skin cancer prevention education approach leads to a higher increase of preventive knowledge and behavioural change compared with an e-learning education programme and a control group (CG).

\section{MATERIALS AND METHODS \\ Study design}

In this randomised controlled comparative study with a waiting list control design, we compared two different intervention schedules with a CG. Randomisation was performed by a computerised block randomisation with a block size of 3 , so that a nearly equal distribution of the participants to the various groups could be achieved. Due to the study design, it was not possible to conduct the study blinded, because except for the basic training it was always clear which group was trained.

\section{Intervention}

For all participants the programme started with the offer of a professional skin examination by a dermatologist and basic training. Contents of this training were, for example, skin variations under immunosuppression like acne or warts and the appropriate skin care. ${ }^{21}$ After completing the general training, the different interventions were conducted according to the randomised groups (figure 1). Participants of the intervention group 1 (IG1) took part in a detailed training in a classical face-toface-situation. Elements of the training were, for example, UV radiation and the UV index (UVI), the different skin types according to Fitzpatrick, the meaning of the light protection factor (LPF), possibilities of the UV light protection (eg, textile sun protection, sunscreen with sufficiently high LPF and in sufficient quantity, avoidance of the midday sun) and the meaning of the Asymmetry, Border, Colour, Diameter, Elevation/Evolving (ABCDE) rule. UVI-dependent sun protection recommendations were sent via SMS twice a week for a time frame of 6 weeks using the sun protection traffic light (table 1). The text messages summarised the local weather forecast for the hours around noon where the most intense UV radiation occurs, based on participant's local UVI and included a behavioural message. The Deutscher Wetterdienst (German Meteorological Service) provided the forecasts of local weather and UVI and sent the SMS.

For the participants of the intervention group 2 (IG2) a $16 \mathrm{~min}$ short video (e-learning education) was available after registration on the HIPPOlino homepage ( www.hippolino.net). The video contained the same core elements provided during the personal training.

Participants of the CG received a biannual information letter about skin care under immunosuppression and were offered the e-learning programme after 1 year.

\section{Data collection}

The improvement of behavioural strategies and knowledge regarding UV light prevention was quantified by a cognitive interviewing validated self-administered questionnaire. The questionnaire was tested beforehand in a pretest by retrospective cognitive interviewing of 31 children and adolescents or their parents-all transplant patients-in the paediatric-nephrological department of the Hannover Medical School. In order to be able to detect short and medium-term changes in the current study, four survey dates were chosen: T0 (at baseline), T1 (6 weeks after intervention; at the time of termination of SMS sending), T2 (after 6 months) and T3 (after 12 months). Parents responded as proxies for children $<12$ years. The survey was conducted exclusively by paper questionnaires.

\section{Covariates}

Demographic information was collected in the baseline questionnaire. Participants were classified as either children ( $<12$ years) or adolescents ( $\geq 12$ years). The current school level of all participants, that is, children and adolescents, was categorised as primary education, lower secondary education, upper secondary education and postsecondary non-tertiary education. Migration background was defined as having at least one parent who was not born in Germany. In addition, age at which the first or only transplantation took place was considered.

\section{Study population and training appointments}

OTRs had to be between 5 and 22 years old and German speaking. In addition to an ongoing immunosuppression during the study period, skin type had to be classified as type I, II or III according to the Fitzpatrick phototyping scale. ${ }^{22}$ Further inclusion criteria were daily access to a mobile phone (for children: by their parents), written consent to the study (when $<18$ years, consent of parents/legal guardians) and the waiving of medical 


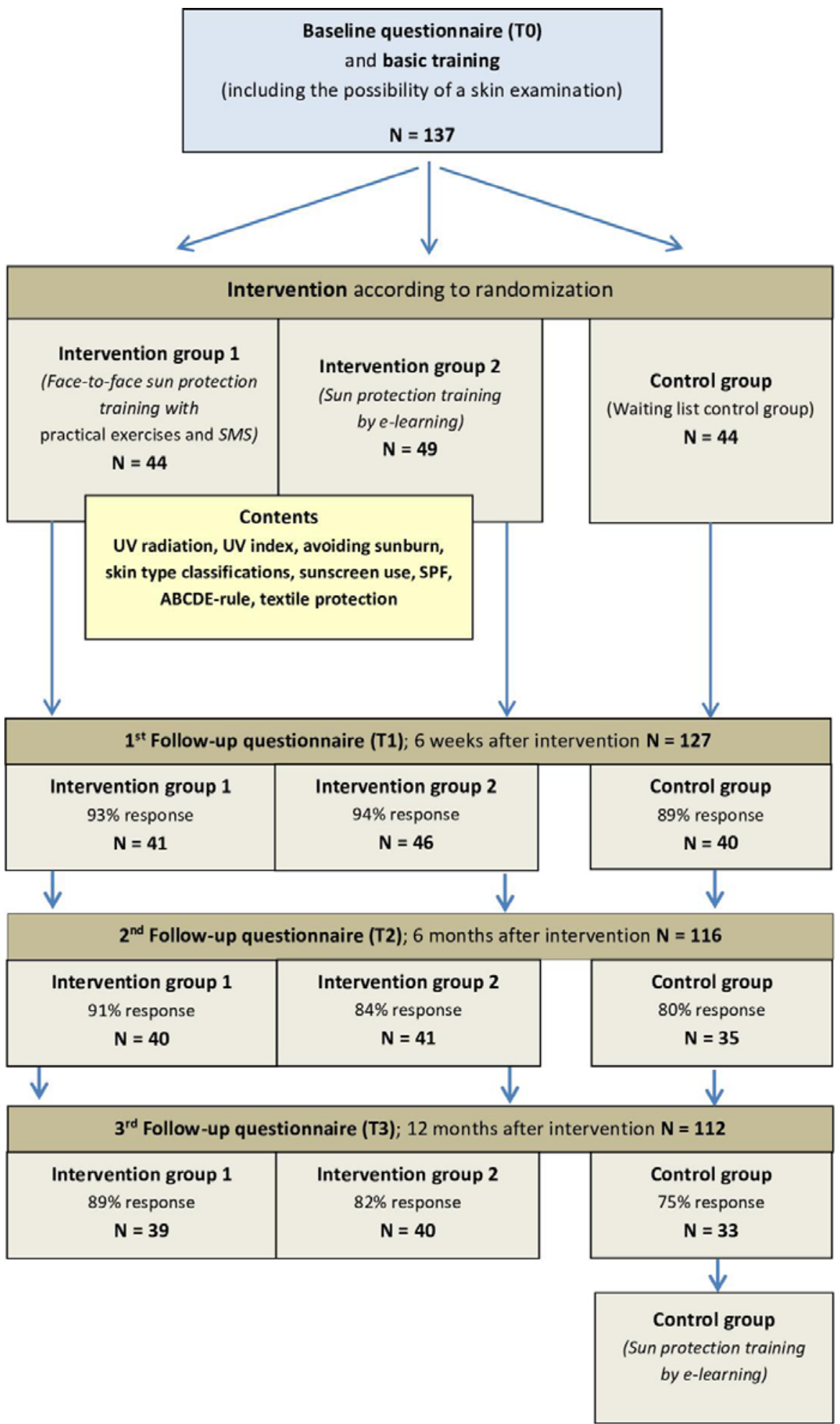

Figure 1 Study design. ABCDE, Asymmetry, Border, Colour, Diameter, Elevation/Evolving; SMS, short message service; SPF, sun protection factor; UV, ultraviolet.

confidentiality. All participants had to complete the baseline questionnaire and take part in the basic training. For children $(<12$ years $)$, a parent had to take part in the training.

The OTRs were recruited via parents' associations and transplantation centres with the help of posters and flyers as well as via a HIPPOlino Facebook site.
Overall, 18 standardised sun protection trainings were conducted by a dermatologist (MMS) and a health scientist (SB) between June 2013 and September 2015 (but only in the spring and summer months between March and September). Fifteen trainings were carried out in different German cities (Bad Oeynhausen, Essen, Frankfurt (Main), Hamburg, Heidelberg, Hannover, Köln, 
Table 1 Example texts of the SMS intervention

\section{Green sun protection traffic lights (UV index range 0-2)}

- Hello! Today the sun traffic lights are GREEN. There is no increased risk of sunburn today. Do you remember the ABCDE rule? A-Asymmetry, B-Border, C-Colour, D-Diameter, E-Elevation/Evolving. Have a nice weekend!

- $\mathrm{Hi}$, the sun traffic lights are back to GREEN. You probably don't have to put on any sunscreen today. Maybe you can still catch some shafts of sunlight. As a reminder: What does the UV index mean? The UV index is a measure for the maximum daily biologically effective radiation from the sun. Take care!

\section{Yellow sun protection traffic lights (UV index range 3-5)}

- Good morning! The sun traffic lights are YELLOW! Today the sun seems quite strong. Keep in mind: There is no sunscreen for your eyes: What about cool sunglasses? Have a nice day!

- Good morning! The sun traffic lights are YELLOW now. Today there is a risk of sunburn, so don't forget the sunscreen! And remember to put some on your nose and ears, a sunburn can be very painful there! See you!

\section{Red sun protection traffic lights (UV index 6 or higher)}

- Attention! Today the sun traffic lights are RED. Today there is a high risk of getting burned and it will get really hot! But with a cool hat, you keep a cool head! Just make sure, that you are slathered with sunscreen, even in the shade because sunrays can reach you there as well! Goodbye!

- Attention! Today the sun traffic lights are RED again! Within a short period of time you can get a nasty sunburn. Remember: the water surface and sand reflect UV radiation! See you!

\section{Sun protection traffic lights in combination with the local cloudiness}

Good morning! The sun traffic lights are YELLOW today! It's a little bit cloudy outside. Nevertheless, you can get a serious sunburn on overcast days if you spent time outside without any sun protection. Take care!

- Hello! Today the sun traffic lights are RED! There are some clouds on the move, BUT remember: sun's UV rays can pass through clouds. So don't forget to on any sunscreen! See you!

SMS, short message service; UV, ultraviolet.

Leipzig, Marburg, Memmingen, München, Oldenburg, Stuttgart, Thale, Tübingen), three trainings were carried out during summer camps in the Netherlands (Enkhuizen) and Austria (two times Stronach). Sample size calculations were determined a priori and based on an expected intervention effect of at least 25 percentage points derived from preliminary investigations and the assumption of a probability of error of alpha $=5 \%$ and a power of $90 \%$ indicated that 80 participants per group would be required.

\section{Patient involvement}

Development of the research question originated from patients' experiences of a former feasibility study. ${ }^{21}$ Patients were not involved in the design of the study. Recruitment and conduction of the study were performed by the authors mentioned in the section heading "Footnotes". Results of this study were also disseminated to study participants by mail. Participants of the study as well as their parents were thanked in the Acknowledgements section.

\section{Definition outcomes}

Recall of the main contents of the training was assessed at all four survey time points (T0-T3). To our knowledge, no validated instrument was available to assess sun protection knowledge and sun protection behaviour. Hence, different multiple-choice key questions were used to form a knowledge score and a behavioural score that we used to quantify our outcomes and track changes over time.
Sun protection knowledge

- Knowing that letters of the ABCDE rule stand for A-Asymmetry, B-Border, C-Colour, D-Diameter, E-Elevation/Evolving (1 point for each correct answer, max 5 points).

- Knowing that the LPF is a multiplier for the duration of time an individual's skin can protect itself from UV exposure, and that it indicates how long an individual can stay in the sun without developing skin damage/ sunburn ( 1 point possible).

- Knowing that the UVI describes the daily peak value of the sunburn effective UV radiation expected at the ground (1 point possible).

\section{Sun protection behaviour}

- To apply sunscreen during summer months (April to October) almost daily, even if it is partly cloudy ( 1 point possible)

- To apply sunscreen on face, ears, neck, arms/hands and legs/feet when wearing a T-shirt and a pair of shorts while being exposed to sunshine (1 point for each correct answer, max 5 points).

- To wear a headgear (eg, baseball cap, cap with neck protection, wide-brimmed hat), a long-sleeved shirt, long trousers/a long skirt and sunglasses while being exposed to sunshine ( 1 point for each correct answer, max 4 points).

\section{Statistical analyses}

Two scores were built to quantify sun protection knowledge and behaviour based on the sum of key questions 
the participants had correctly answered. The scores ranged from 0 to 7 for the knowledge and from 0 to 10 for the behavioural score. Answers to key questions from preintervention and postintervention questionnaires as well as scores were considered in longitudinal difference models to identify positive changes in knowledge and in behaviour. Hence, to investigate short-term effects, correct answers on key questions in $\mathrm{T} 1$ together with wrong answers at baseline (T0) were coded as improvement (1) in knowledge or behaviour, while no change or change for the worse in answer from T0 to T1 was coded as no improvement (0). Differences between scores were also calculated and again categorised as improvement (1) showing a positive change and no improvement (0) for no change or change for the worse. Difference models for T2 and T3 were applied the same way to estimate midterm effects of interventions. Logistic regression models were used to investigate the effect of the intervention (IG1 or IG2) compared with CG on the improvement of sun protection knowledge or behaviour by means of ORs and 95\% CIs. Single key questions as well as overall scores of sun protection knowledge or behaviour were used as outcome variables. All models were adjusted for age group, sex, migration status, type of school and age at which the (first) transplantation took place. Logistic regression analysis was performed using PROC LOGISTIC in SAS V.9.3 (SAS Institute).

\section{RESULTS}

\section{Participants' characteristics}

One hundred and thirty-seven participants ( 61 females $/ 76$ males) were included in the study. The average age was 12.6 years. All participating children and adolescents (or parents as proxies for young children) completed the baseline questionnaire (T0) and took part in the training programme according to their study group: 44 participants (22 females/22 males) were randomised in IG1, 49 participants (18/31) in IG2 and 44 participants (21/23) in CG (see figure 1). Eighteen participants of the IG2 $(11 / 7)$ registered for the online training (37\% response rate; total $n=49$ ).

Overall, 127 of 137 participants completed the first follow-up questionnaire (T1) (93\% response rate), 116 the second follow-up questionnaire (T2) (85\%) and 112 the third follow-up questionnaire (T3) (82\%).

Sociodemographic and basic characteristics such as migrant background, education and age at the time of the transplantation were evenly distributed across all three study groups (table 2).

\section{Sun protection knowledge}

The descriptive evaluation showed that the sun protection knowledge was low in all groups at T0. Fifty per cent of the participants from both the IGs and the CG only had 1 out of 7 points (median, IQR 1-2). At T1, a distinct increase of knowledge was visible within IG1. Half of the participants in the group attained 6 or 7 points. At T3,
$50 \%$ of the IG1 still reached a median value of 5 points. Comparatively, there was no knowledge increase or a small increase of about one score point in IG2 and CG (table 3).

The regression analyses of the knowledge score showed that IG1 participants had a significant higher chance to improve their sun protection knowledge at all three survey points compared with the CG (T1: OR 12.64, 95\% CI 4.20 to 38.2; T2: OR 12.54, $95 \%$ CI 3.79 to 41.47; T3: OR 4.46, 95\% CI 1.48 to 13.43). Participants of the IG2 showed a much smaller, statistically non-significant increase in the overall knowledge (T1: OR 2.59, 95\% CI 0.95 to 7.04 ; T2: OR 2.71, 95\% CI 0.91 to 8.13; T3: OR $1.41,95 \%$ CI 0.51 to 3.93) (table 4). Similar results were illustrated by the evaluations of the single key questions regarding knowledge. At all three follow-up points the participants of the IG1 had significantly higher chances of giving correct answers compared with the CG (table 4). The participants of the IG2 were only more likely to improve their knowledge regarding the ABCDE mnemonic at all survey points, but fared worse that the CG for the UVI and the sun protection factor question at the subsequent time points (table 4).

\section{Sun protection behaviour}

The self-reported sun protection behaviour was 6 points (median) (IQR 5-7) before the intervention and remained stable during the entire survey period. A low improvement was measured in IG1 at T3 (IQR 8-6) (table 3).

The regression analysis of the behavioural score demonstrated that the participants of the IG1 were more likely to improve their behaviour than the participants of the CG at T1. However, at T2 and T3 no differences between IG1 and CG could be seen (T1: OR 2.56, 95\% CI 0.93 to 7.0; T2: OR 0.98, $95 \%$ CI 0.35 to 2.7; T3: OR $1.06,95 \%$ CI 0.38 to 2.93) (table 4). Within the IG2 there were no differences compared with the CG (table 4). The results showed an improvement 6 weeks and 6 months after the intervention concerning the daily use of sunscreen during summer months and applying sunscreen on uncovered body areas of both IGs compared with the CG. The participants of the IG1 had a higher chance for an improvement (table 4). The results for wearing sun protection clothes like long-sleeved clothes, hat and sunglasses showed no differences compared with IG1 and CG at any survey point. The participants of the IG2 reported this form of sun protection even less often than the CG (table 4).

\section{DISCUSSION}

The main objective of this study was the evaluation of an innovative training programme for skin cancer prevention in young OTRs. According to our knowledge, this is the first intervention study in Germany evaluating sun protection knowledge and behaviour of OTRs using mHealth and eHealth training approaches. Children and adolescents from all over the country were included, 
Table 2 Characteristics of study population at TO

\begin{tabular}{|c|c|c|c|c|c|c|c|c|}
\hline \multirow[b]{3}{*}{ Characteristics } & \multirow{2}{*}{\multicolumn{2}{|c|}{$\begin{array}{l}\text { All } \\
(n=137)\end{array}$}} & \multicolumn{6}{|c|}{ Groups } \\
\hline & & & \multicolumn{2}{|c|}{$\begin{array}{l}\text { Intervention } 1 \\
(n=44)\end{array}$} & \multicolumn{2}{|c|}{$\begin{array}{l}\text { Intervention } 2 \\
(\mathrm{n}=49)\end{array}$} & \multicolumn{2}{|c|}{$\begin{array}{l}\text { Control } \\
(n=44)\end{array}$} \\
\hline & $\mathbf{n}$ & $\%$ & $\mathbf{n}$ & $\%$ & $\mathbf{n}$ & $\%$ & $\mathbf{n}$ & $\%$ \\
\hline \multicolumn{9}{|l|}{ Age (years) } \\
\hline 5-11 (children) & 56 & 40.9 & 18 & 40.9 & 16 & 32.7 & 22 & 50.0 \\
\hline 12-21 (adolescents) & 81 & 59.1 & 26 & 59.1 & 33 & 67.3 & 22 & 50.0 \\
\hline \multicolumn{9}{|l|}{ Sex } \\
\hline Male & 76 & 55.5 & 22 & 50.0 & 31 & 63.3 & 23 & 52.3 \\
\hline Female & 61 & 44.5 & 22 & 50.0 & 18 & 36.7 & 21 & 47.7 \\
\hline \multicolumn{9}{|l|}{ Migrant background } \\
\hline No & 107 & 78.1 & 35 & 79.5 & 37 & 75.5 & 35 & 79.5 \\
\hline Yes & 30 & 21.9 & 9 & 20.5 & 12 & 24.5 & 9 & 20.5 \\
\hline \multicolumn{9}{|l|}{ School education* } \\
\hline Preschool/primary school (<grade 5) & 39 & 28.5 & 10 & 22.7 & 11 & 22.4 & 18 & 40.9 \\
\hline Basic level school/special school & 18 & 13.1 & 6 & 13.6 & 7 & 14.3 & 5 & 11.4 \\
\hline Middle school/comprehensive school & 43 & 31.4 & 18 & 40.9 & 14 & 28.6 & 11 & 25.0 \\
\hline High school/technical secondary school & 35 & 25.5 & 10 & 22.7 & 16 & 32.7 & 9 & 20.5 \\
\hline Missings & 2 & 1.5 & . & . & 1 & 2.0 & 1 & 2.3 \\
\hline \multicolumn{9}{|l|}{ Age at time of transplantation } \\
\hline $0-5$ & 71 & 51.8 & 27 & 61.4 & 21 & 42.9 & 23 & 52.3 \\
\hline $6-11$ & 35 & 25.5 & 9 & 20.5 & 18 & 36.7 & 8 & 18.2 \\
\hline $12-18$ & 30 & 21.9 & 7 & 15.9 & 10 & 20.4 & 13 & 29.5 \\
\hline Missings & 1 & 0.7 & 1 & 2.3 & . & . & . & . \\
\hline \multicolumn{9}{|l|}{ Transplanted organ $†$} \\
\hline Kidney & 71 & 51.8 & 19 & 43.2 & 33 & 67.3 & 19 & 43.2 \\
\hline Liver & 56 & 40.9 & 19 & 43.2 & 15 & 30.6 & 22 & 50.0 \\
\hline Heart & 14 & 10.2 & 7 & 15.9 & 2 & 4.1 & 5 & 11.4 \\
\hline Other & 2 & 1.5 & 1 & 2.3 & . & . & 1 & 2.27 \\
\hline \multicolumn{9}{|l|}{ Family history of skin cancer } \\
\hline No & 96 & 70.1 & 29 & 65.9 & 34 & 69.4 & 33 & 75.0 \\
\hline Yes & 23 & 16.8 & 9 & 20.5 & 11 & 22.4 & 3 & 6.8 \\
\hline Missings & 18 & 13.1 & 6 & 13.6 & 4 & 8.2 & 8 & 18.2 \\
\hline
\end{tabular}

${ }^{*}$ Current or completed school form (in Germany) at time of the training.

†Multiple references possible.

thus limiting bias due to, for example, specific regional weather conditions and individual dermatological follow-up programmes. A successful feasibility study had been conducted earlier. ${ }^{21}$ Participants of both IG had an increase in knowledge compared with the CG. The evaluation of the single key questions demonstrated, however, that the medium-term knowledge increase within the IG2 only referred to the ABCDE rule. Notably, participants of the IG1 generally showed significantly higher levels of improvements. This finding supports the effectiveness of personal training combined with individualised messaging in this context. Earlier studies showed that a short-term increase of knowledge in general population groups could be reached through trainings. ${ }^{23}{ }^{24}$ In contrast to Vuong et al who could not demonstrate any knowledge differences after general practitioner delivered sun protection advice, ${ }^{25}$ our study showed a medium-term knowledge increase for IG1. However, comparability between studies is limited as the contents of the knowledge questions vary. The most frequently asked questions in previous studies often relate, for example, to the general risk of skin cancer or general sun protection measures. ${ }^{23-27}$ The questions in our study addressed rather detailed contents, probably leading to the low knowledge levels before the intervention and the strong increase afterwards, as was also seen in a related study among nursing students. ${ }^{28}$ 
Table 3 Descriptions of changes in knowledge and behavioural scores

\begin{tabular}{|c|c|c|c|c|c|c|c|c|c|c|c|c|}
\hline & \multicolumn{3}{|l|}{ TO } & \multicolumn{3}{|l|}{ T1 } & \multicolumn{3}{|l|}{ T2 } & \multicolumn{3}{|l|}{ T3 } \\
\hline & $\mathbf{n}$ & Median & IQR & $\mathbf{n}$ & Median & IQR & $\mathbf{n}$ & Median & IQR & $\mathbf{n}$ & Median & IQR \\
\hline \multicolumn{13}{|c|}{ Knowledge score (range $0-7$ ) } \\
\hline Intervention 2 & 46 & 1 & $1-0$ & 46 & 1 & $2-1$ & 41 & 1 & $4-1$ & 40 & 2 & $5-1$ \\
\hline Control & 40 & 1 & $2-1$ & 40 & 1 & $2-1$ & 35 & 1 & $2-1$ & 33 & 2 & $3-1$ \\
\hline Intervention 1 & 41 & 6 & $7-6$ & 41 & 7 & $7-6$ & 39 & 7 & $7-6$ & 38 & 7 & $8-6$ \\
\hline Intervention 2 & 45 & 6 & $7-5$ & 46 & 6 & $7-5$ & 41 & 6 & $7-5$ & 40 & 6 & $7-6$ \\
\hline Control & 38 & 6 & $7-5$ & 39 & 6 & $7-6$ & 35 & 7 & $7-6$ & 33 & 6 & $7-6$ \\
\hline
\end{tabular}

Concerning the reported sun protection behaviour, participants of the IG1 only showed a non-significant short-term improvement in comparison to the CG. Up to 6 months after the intervention no differences were found, neither between both IGs nor in comparison to the CG. Concerning the low intervention effects within the groups it should be considered that all participants of the HIPPOlino study reported a good sun protection behaviour at all survey points. Previous studies reported mixed findings. While Fernández-Morano et al

Table 4 Changes over time of sun protection knowledge and behaviour

\begin{tabular}{|c|c|c|c|c|c|c|c|c|c|c|}
\hline & \multirow{2}{*}{$\begin{array}{l}\text { Group } \\
\text { (ref: control) }\end{array}$} & \multicolumn{3}{|c|}{ T1 versus T0 } & \multicolumn{3}{|c|}{$\mathrm{T} 2$ versus T0 } & \multicolumn{3}{|c|}{ T3 versus T0 } \\
\hline & & $n$ & $\mathbf{R}$ & OR $(95 \% \mathrm{Cl})^{*}$ & $\mathbf{n}$ & $\mathbf{R}$ & OR $(95 \% \mathrm{Cl})$ & $n$ & $\mathbf{R}$ & OR $(95 \% \mathrm{Cl})$ \\
\hline \multicolumn{11}{|l|}{$\begin{array}{l}\text { Sun protection } \\
\text { KNOWLEDGE }\end{array}$} \\
\hline \multirow[t]{2}{*}{ Score } & Intervention 1 & 125 & 0.30 & 12.64 (4.20 to 38.20$)$ & 114 & 0.34 & 12.54 (3.79 to 41.47$)$ & 110 & 0.20 & 4.46 (1.48 to 13.43$)$ \\
\hline & Intervention 2 & & & 2.59 (0.95 to 7.04$)$ & & & 2.71 (0.91 to 8.13$)$ & & & 1.41 (0.51 to 3.93$)$ \\
\hline \multirow[t]{2}{*}{$\begin{array}{l}\text { Meaning of letters of } \\
\text { the 'ABCDE-rule' }\end{array}$} & $\begin{array}{l}\text { Intervention } 1 \\
\text { Intervention } 2\end{array}$ & 125 & 0.31 & 11.36 (3.43 to 37.61$)$ & 114 & 0.45 & $\begin{array}{l}28.44 \text { (4.92 to } \\
164.32)\end{array}$ & 110 & 0.25 & 5.03 (1.65 to 15.34$)$ \\
\hline & & & & 2.25 (0.67 to 7.70$)$ & & & 9.20 (1.65 to 51.28$)$ & & & $1.41(0.45$ to 4.38$)$ \\
\hline \multirow{2}{*}{$\begin{array}{l}\text { Meaning of the sun } \\
\text { protection factor } \\
\text { (SPF) }\end{array}$} & Intervention 1 & 125 & 0.15 & 4.78 (1.03 to 21.96$)$ & 114 & 0.27 & 4.66 (1.01 to 21.59$)$ & 110 & 0.22 & 2.08 (0.43 to 9.67$)$ \\
\hline & Intervention 2 & & & $1.86(0.40$ to 8.70$)$ & & & $0.84(0.15$ to 4.75$)$ & & & $0.43(0.07$ to 2.54$)$ \\
\hline $\begin{array}{l}\text { Meaning of the UV } \\
\text { index }\end{array}$ & Intervention 1 & 125 & 0.16 & 4.44 (1.51 to 13.00$)$ & 114 & 0.17 & 2.42 (0.86 to 6.81$)$ & 110 & 0.16 & 1.40 (0.49 to 3.97$)$ \\
\hline \multicolumn{11}{|l|}{$\begin{array}{l}\text { Sun protection } \\
\text { BEHAVIOUR }\end{array}$} \\
\hline Score & Intervention 2 & & & $1.22(0.45$ to 3.32$)$ & & & 0.61 (0.22 to 1.70$)$ & & & $1.13(0.41$ to 3.09$)$ \\
\hline \multirow{2}{*}{$\begin{array}{l}\text { Applying sunscreen } \\
\text { during summer } \\
\text { month (April to } \\
\text { October) }\end{array}$} & Intervention 1 & 125 & 0.25 & 5.33 (0.51 to 55.69$)$ & 114 & 0.24 & $\begin{array}{l}11.11 \text { ( } 0.98 \text { to } \\
125.29)\end{array}$ & 110 & 0.30 & 1.65 (0.38 to 7.20$)$ \\
\hline & Intervention 2 & & & 2.32 (0.18 to 29.65$)$ & & & $3.13(0.27$ to 36.91$)$ & & & 0.21 (0.02 to 2.29$)$ \\
\hline \multirow{2}{*}{$\begin{array}{l}\text { Applying sunscreen } \\
\text { on uncovered body } \\
\text { parts while being in } \\
\text { sunshine }\end{array}$} & Intervention 1 & 125 & 0.19 & 1.95 (0.59 to 6.43$)$ & 114 & 0.20 & $1.86(0.47$ to 7.30$)$ & 110 & 0.22 & 1.32 (0.29 to 6.09$)$ \\
\hline & Intervention 2 & & & 1.89 (0.61 to 5.87$)$ & & & $1.62(0.43$ to 6.14$)$ & & & 3.51 (0.86 to 14.39$)$ \\
\hline \multirow{2}{*}{$\begin{array}{l}\text { Wearing clothes } \\
\text { (headgear, long- } \\
\text { sleeved, and so } \\
\text { on) while being in } \\
\text { sunshine }\end{array}$} & Intervention 1 & 125 & 0.19 & 1.17 (0.42 to 3.28$)$ & 114 & 0.12 & 0.84 (0.31 to 2.26$)$ & 110 & 0.09 & 1.13 (0.40 to 3.23$)$ \\
\hline & Intervention 2 & & & 0.44 (0.15 to 1.35$)$ & & & $0.39(0.14$ to 1.11$)$ & & & 0.76 (0.26 to 2.19$)$ \\
\hline
\end{tabular}

Models were adjusted for age group, sex, migrant background, education, age at time of transplantation.

The significant results are shown in bold types.

${ }^{*}$ ORs and $95 \%$ confidence limits (Cl) for intervention effects based on multivariate logistic regressions modelling positive changes (improvement from T0 to T1, T2 or T3, respectively) in scores key questions with regard to sun protection knowledge and behaviour of skin cancer prevention.

ABCDE, Asymmetry, Border, Colour, Diameter, Elevation/Evolving; UV, ultraviolet. 
demonstrated a short-term improvement of sun protection behaviour among non-immunosuppressed adolescents following a special training programme, ${ }^{26}$ other studies did not result in any significant improvement of protective behaviour. ${ }^{2325} 29$

Recent mobile technology-based studies on skin cancer prevention similarly demonstrated an increase of knowledge regarding the risk of skin cancer, whereas the sun protection behaviour improved only for a short time. This was mainly related to behavioural strategies such as the use of sunscreen or textile protection. ${ }^{16} 17$ The results of our study show an improvement regarding the use of sunscreen in both IGs. The textile sun protection behaviour however did not improve in the IGs in comparison to the CG. In a study with 101 adult OTRs, Robinson et al showed that an intervention combined with electronic reminders influenced knowledge increase regarding skin cancer and sun protection after 6 weeks. ${ }^{27}$ Like in our study, there were no significant differences between the groups at the beginning. Further, 6 weeks after the intervention there was no significant improvement of the behaviour regarding textile protection, the use of sunscreen and the reduction of the average weekly sunlight exposure. ${ }^{27}$

Our study had some limitations. Neither the researchers nor the participants were blinded. Due to the small sample size statistical power was limited. It is possible that the low motivation to participate is due to the fact that sun protection is not a primary issue after organ transplantation. Furthermore, there was a low willingness to participate in the e-learning programme, possibly due to the requirement to separately register for this programme. However, studies also show that students and participants of health interventions prefer face-to-face training. ${ }^{11}{ }^{12}$ Similar to other behavioural studies, factors such as self-report, social desirability and recall bias may have influenced our findings, as well as lack of blinding which was not feasible in this study. ${ }^{20}{ }^{23} \mathrm{An}$ additional limitation is the possible selection bias, where parents, children and adolescents with a high interest in the topic might be more likely to be recruited, with subsequently reduced potential for intervention effects. Overall, these limitations call for cautious interpretation of results, but the heterogeneous findings at different time points may be seen to support the notion of limited, but real differences between the groups with respect to the studied outcomes.

\section{CONCLUSIONS}

In summary, mHealth education combined with face-toface-training showed a stronger effect on relevant sun protection knowledge and behaviour compared with an eHealth education among young OTRs. Face-to-facetraining with subsequent forwarding of individual UVIdependent sun protection recommendations via SMS increased the short and medium-term sun protection knowledge. However, there were at best minor effects on UV preventive behaviours. In fact, the well-being and the worry about the state of health of the children (eg, the fear of a transplant rejection) play a decisive role. Thus, while there is an increase in knowledge, the comparative relevance of a UV-related behaviour change may still be low.

We cautiously conclude that SMS-supported personal skin cancer prevention education can be considered as a promising strategy for knowledge improvement. Future advances in data collection strategies, intervention study design and conduct are necessary to strengthen skin cancer prevention research in transplant recipients. Larger sample sizes and tailored interventions contrasting eHealth and mHealth approaches with faceto-face training will be useful in this regard.

\section{Author affiliations}

${ }^{1}$ Leibniz-Institut für Präventionsforschung und Epidemiologie-BIPS, Bremen, Germany

${ }^{2}$ High-Profile Research Area Health Sciences, University of Bremen, Bremen, Germany

${ }^{3}$ Deutscher Wetterdienst, Freiburg, Germany

${ }^{4}$ Bremen Cancer Society, Bremen, Germany

${ }^{5}$ Department of Dermatology, Allergology and Phlebology, Klinikum Bremerhaven Reinkenheide, Bremerhaven, Germany

Acknowledgements The authors thank all the children and adolescents and their parents for the participation. The authors thank Ingeborg Jahn for her role in the study concept and funding application and Beate Schütte, Stephanie PreyerReupsch, Stephan Janisch and Funda Klein-Ellinghaus for their support during the study planning and conduct. The authors also express gratitude to the members and employees of the parental associations and transplantation centres in Germany for the help with the recruitment of the participants, for providing rooms and for the takeover of the caterings and for kindly providing their time and assistance.

Contributors SB, CB and $\mathrm{HZ}$ had full access to all study data and take responsibility for the integrity of the data and the accuracy of the data analysis. Study concept and design: MMS, SB. Acquisition, analysis and interpretation of data: $\mathrm{CB}, \mathrm{SB}, \mathrm{MMS}, \mathrm{HZ}$. Drafting of the manuscript: $\mathrm{SB}, \mathrm{CB}, \mathrm{CH}, \mathrm{MMS}, \mathrm{HZ}$. Critical revision of the manuscript for important intellectual content: $\mathrm{SB}, \mathrm{CH}, \mathrm{MMS}, \mathrm{GL}, \mathrm{HZ}$. Statistical analysis: CB. Obtained funding: SB, MMS, HZ. Administrative, technical or material support: GL, GW. Study supervision: $\mathrm{SB}, \mathrm{MMS}, \mathrm{GW}, \mathrm{HZ}$.

Funding The publication of this article was funded by the Open Access Fund of the Leibniz Association. This work was supported by the German Cancer Aid ('Deutsche Krebshilfe e.V.') (grant number 110861).

Competing interests HZ, MMS and SB report grants from German Cancer Aid, during the conduct of the study.

\section{Patient consent for publication Not required.}

Ethics approval This study was conducted in accordance with the Declaration of Helsinki and was approved by the Ethics Review Board of the University of Bremen.

Provenance and peer review Not commissioned; externally peer reviewed.

Data availability statement All data relevant to the study are included in the article or uploaded as supplementary information.

Open access This is an open access article distributed in accordance with the Creative Commons Attribution Non Commercial (CC BY-NC 4.0) license, which permits others to distribute, remix, adapt, build upon this work non-commercially, and license their derivative works on different terms, provided the original work is properly cited, appropriate credit is given, any changes made indicated, and the use is non-commercial. See: http://creativecommons.org/licenses/by-nc/4.0/.

\section{REFERENCES}

1 Deutsche Krebsgesellschaft, Deutsche Krebshilfe, AWMF. Leitlinienprogramm Onkologie. S3-Leitlinie Prävention von Hautkrebs, 2014. Available: http://leitlinienprogramm-onkologie.de/ Leitlinien.7.0.html [Accessed 28 Jun 2016]. 
2 Hackethal M, Ulrich C, Stockfleth E. Hauttumore nACh Organtransplantation. Dtsch Med Wochenschr 2006;131:1609-13.

3 Ulrich C, Schmook T, Sachse MM, et al. Comparative epidemiology and pathogenic factors for nonmelanoma skin cancer in organ transplant patients. Dermatol Surg 2004;30:622-7.

4 Leiter U, Garbe C. Hauttumoren bei organtransplantierten Patienten. Epidemiologie und management. Hautarzt 2010;61:207-13.

5 Euvrard S, Kanitakis J, Claudy A. Skin cancers after organ transplantation. N Engl J Med 2003;348:1681-91.

6 Butt A, Roberts DL. Renal transplant recipients and protection from sun: need for education. Lancet 1997;349:179-80.

7 Hewitt S, J. Gordon E, Clayman, M, et al. Change in duration of sun exposure 2 years after solid organ transplantation. $J$ Transplant Technol Res 2011;01.

8 Robinson JK, Rigel DS. Sun protection attitudes and behaviors of solid-organ transplant recipients. Dermatol Surg 2004;30:610-5.

9 Faurschou A, Wulf HC. The relation between sun protection factor and amount of suncreen applied in vivo. $\mathrm{Br} J$ Dermatol 2007;156:716-9.

10 Sachse MM, Ehrich JHH, Pape L, et al. SPF 50 for organ transplant patients--over the top? Nephrol Dial Transplant 2009;24.

11 McKenzie K. A comparison of the effectiveness of a game informed online learning activity and face to face teaching in increasing knowledge about managing aggression in health settings. Adv Health Sci Educ Theory Pract 2013;18:917-27.

12 Kemp N, Grieve R. Face-to-face or face-to-screen? Undergraduates' opinions and test performance in classroom vs. online learning. Front Psychol 2014;5:1278.

13 Andersson G, Cuijpers P, Carlbring P, et al. Guided Internet-based vs. face-to-face cognitive behavior therapy for psychiatric and somatic disorders: a systematic review and meta-analysis. World Psychiatry 2014:13:288-95.

14 World Health Organization. mHealth: New horizons for health through mobile technologies. Based on the findings of the second global survey on eHealth. Global Observatory for eHealth series - Volume 3. Available: http://www.who.int/goe/publications/goe_mhealth_web. pdf [Accessed 27 Nov 2017].

15 Miloh T, Annunziato R, Arnon R, et al. Improved adherence and outcomes for pediatric liver transplant recipients by using text messaging. Pediatrics 2009;124:e844-50.

16 Shellmer DA, Dew MA, Mazariegos G, et al. Development and field testing of Teen Pocket PATH(®), a mobile health application to improve medication adherence in adolescent solid organ recipients. Pediatr Transplant 2016;20:130-40.
17 Miloh T, Shub M, Montes R, et al. Text messaging effect on adherence in children with inflammatory bowel disease. J Pediatr Gastroenterol Nutr 2017;64:939-42.

18 Hingle MD, Snyder AL, McKenzie NE, et al. Effects of a short messaging service-based skin cancer prevention campaign in adolescents. Am J Prev Med 2014:47:617-23.

19 Ho BK, Reidy K, Huerta I, et al. Effectiveness of a multicomponent sun protection program for young children: a randomized clinical trial. JAMA Pediatr 2016;170:334-42.

20 Youl PH, Soyer HP, Baade PD, et al. Can skin cancer prevention and early detection be improved via mobile phone text messaging? a randomised, attention control trial. Prev Med 2015;71:50-6.

21 Sachse MM, Böttcher S, Pape L, et al. Face-to-face sun protection training and text messages improve sun protection behaviour in adolescent organ transplant recipients: HIPPOlino feasibility study. Acta Derm Venereol 2016;96:341-5.

22 Eilers S, Bach DQ, Gaber R, et al. Accuracy of self-report in assessing FitzPatrick skin phototypes I through VI. JAMA Dermatol 2013;149:1289-94

23 Miller KA, Langholz BM, Ly T, et al. Sunsmart: evaluation of a pilot school-based sun protection intervention in Hispanic early adolescents. Health Educ Res 2015;30:371-9.

24 Stanganelli I, Naldi L, Falcini F, et al. Parental use and educational campaigns on sunbed use among teenagers and adolescents. Medicine 2016;95:e3034.

25 Vuong K, Trevena L, Bonevski B, et al. Feasibility of a GP delivered skin cancer prevention intervention in Australia. BMC Fam Pract 2014; $15: 137$

26 Fernández-Morano T, de Troya-Martín M, Rivas-Ruiz F, et al Sensitivity to change of the beach questionnaire to behaviour, attitudes and knowledge related to sun exposure: quasi-experimental before-after study. BMC Public Health 2015;15:60.

27 Robinson JK, Guevara Y, Gaber R, et al. Efficacy of a sun protection workbook for kidney transplant recipients: a randomized controlled trial of a culturally sensitive educational intervention. Am J Transplant 2014:14:2821-9.

28 Erkin Özüm, Ardahan M, Temel AB. Effects of creating awareness through Photographs and posters on skin self-examination in nursing students. J Cancer Educ 2018;33:52-8.

29 Reinau D, Meier CR, Gerber N, et al. Evaluation of a sun safety education programme for primary school students in Switzerland. Eur J Cancer Prev 2014;23:303-9. 